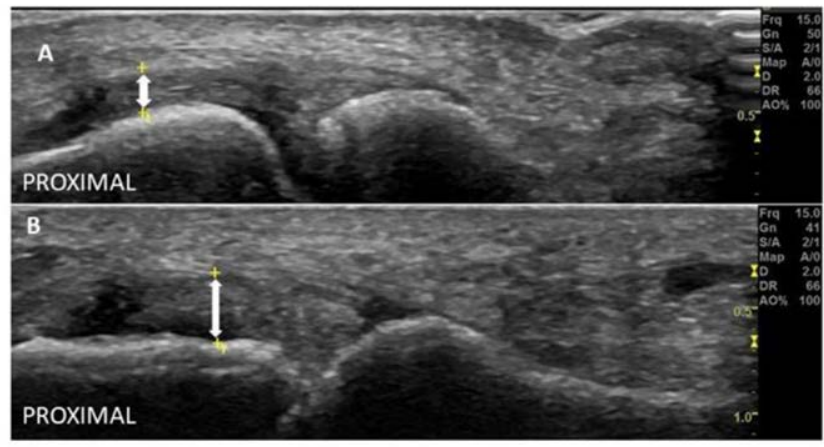

Figure 1. Medial Longitudinal Ultrasound of $1^{\text {st }} M T P$ Joint in Patients with Hyperuricaemia. (A) Normal dMC-MT $(0.22 \mathrm{~cm}-$ block arrows.) (B) Large dMC-MT \& tophus $(0.33 \mathrm{~cm}-$ block arrows.) Greyscale images obtained using Logiq E9 at $15 \mathrm{mHZ}$.

Disclosure of Interests: None declared DOI: 10.1136/annrheumdis-2020-eular.2182

\section{SAT0562 ADDITIONAL BENEFIT OF ULTRASOUND TO THE EARLY DIAGNOSIS OF PSORIATIC ARTHRITIS}

Y. Geng ${ }^{1}$, A. Cope ${ }^{2}$, S. Subesinghe ${ }^{2}$, J. Galloway ${ }^{3}$, Z. Zhang ${ }^{1}$, B. Kirkham ${ }^{2}$ ${ }^{1}$ Peking University First Hospital, Department of Rheumatology and Clinical Immunology, Beijing, China; ${ }^{2}$ Guy's and St Thomas' NHS Trust, Department of Rheumatology, London, United Kingdom; ${ }^{3}$ King's College London, Academic Department of Rheumatology, London, United Kingdom

Background: Being an inflammatory disease of joint, spine or enthesis is the premise of the CASPAR diagnostic criteria for psoriatic arthritis (PsA). Traditionally, the assessment of local inflammation in joint, enthesis and tendon relies on physical examinations. But multiple studies have demonstrated that ultrasound (US) is capable of detecting subclinical inflammation as well as non-inflammatory lesions.

Objectives: To compare the capabilities of physical examination and US findings in the diagnosis of early PSA, and further identify the US features which are most valuable for the diagnosis of PsA.

Methods: 66 patients with suspected PsA or early PsA (disease duration $<2$ years) due to psoriasis with joint pain or seronegative inflammatory arthritis were enrolled and further assessed by both physical examination and ultrasound (US). Tender and swollen joint counts based on $68 / 66$ joints, tender tendons, enthesitis (14 entheses) and dactylitis (20 digits) count were collected by physical examination. Abnormalities of peripheral joints, entheses and tendons were also evaluated by US. New bone formation was evaluated by hand X-ray. The diagnostic capacity of CASPAR criteria based on US and based on physical examination were compared. The diagnosis value of US features as well as clinical characteristics were analyzed. The clinical diagnosis of PsA by the expert panel was taken as the standard.

Results: CASPAR criteria based on US showed a higher specificity than those based on physical examination ( $96.7 \%$ vs. $53.3 \%$ ) with a bit decrease of sensitivity $(91.7 \%$ vs. $97.2 \%)$. 36 patients were eventually diagnosed as PsA and 30 patients were non-PsA. Gender distribution, mean age and disease duration were equally distributed in two groups of patients. Dermatology Life Quality Index (DLQI) was higher in PsA patients than non-PsA patients. Significantly more patients had nail change and new bone formation on hand X-ray in PsA patients than in non-PsA patients $(69.4 \%$ vs. $26.7 \%, P=0.001$ and $66.7 \%$ vs. $13.3 \%, P<0.001$ respectively). Significantly higher frequencies of synovitis/ synovium hypertrophy, tenosynovitis and enthesitis were found in PsA patients than non-PsA patients $(58.3 \%$ vs $20.0 \%, P=0.002,38.9 \%$ vs $3.3 \%, P=0.001$ and $52.8 \%$ vs $13.3 \%, P=0.002$, respectively). Logistic regression analysis showed that nail change $(\mathrm{OR}=25.1, \mathrm{P}=0.007)$, new bone formation on $\mathrm{X}$-ray $(\mathrm{OR}=33.1$, $\mathrm{P}=0.003)$, tenosynovitis on US (OR=149.1, $\mathrm{P}=0.003)$ and enthesitis on US $(\mathrm{OR}=39.2, \mathrm{P}=0.008)$ were independent risk factors for predicting the diagnosis of PsA.

Conclusion: US increased the specificity of CASPAR criteria compared with physical examination. Combined nail change, new bone formation on X-ray, tenosynovitis and enthesitis on US improved the diagnosis of early PsA. References:
[1] Polachek A, Cook R, Chandran V, et al. The association between sonographic enthesitis and radiographic damage in psoriatic arthritis. Arthritis Res Ther 2017; 19(1): 189.

[2] Faustini F, Simon D, Oliveira I, et al. Subclinical joint inflammation in patients with psoriasis without concomitant psoriatic arthritis: a cross-sectional and longitudinal analysis. Ann Rheum Dis 2016; 75(12): 2068-74.

Acknowledgments: The author thank all the colleagues in the department of Rheumatology of Guy's hospital.

Disclosure of Interests: None declared

DOI: 10.1136/annrheumdis-2020-eular.5123

\section{SAT0563 SINGLE-PHOTON EMISSION COMPUTED TOMOGRAPHY-COMPUTED TOMOGRAPHY IS EQUIVALENT TO MAGNETIC RESONANCE IMAGING IN THE EARLY DIAGNOSIS OF SPONDYLOARTHRITIS: A RETROSPECTIVE STUDY}

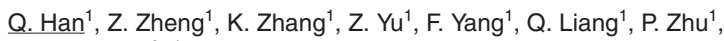
X. Baraliakos ${ }^{2}{ }^{1}$ Department of Clinical Immunology, PLA Specialized Research Institute of Rheumatology \& Immunology, Xijing Hospital, Fourth Military Medical University, Xi'an, China; ${ }^{2}$ Rheumazentrum Ruhrgebiet Herne, RuhrUniversity Bochum, Herne, Germany

Background: SpA has historically been a difficult clinical diagnosis, especially early diagnosis. Two imaging techniques that address this problem are magnetic resonance imaging (MRI) and Single-Photon Emission Computed Tomography-Computed Tomography (SPECT-CT). Their accuracies have not been adequately compared.

Objectives: The purpose of this study is to compare the sensitivities and specificities of SPECT-CT and MRI in SpA.

Methods: This retrospective study assessed all patients who underwent SPECT-CT of the sacroiliac joint to assess for SpA. The results of SPECT-CT were compared against MRI for all patients in the cohort who underwent an MRI within 4 weeks of the SPECT-CT. A diagnosis of SpA in the discharge summary was considered the reference standard, and was based on a combination of clinical scenario, response to therapy, imaging,, patient history or lab index.

Results: 200 patients (173 men; average $22 \pm 4$ years of age) were included SpA was diagnosed in 189 (AS patients=99 and excluded in 11. SPECT-CT and MR had similar ( $P>0.05 ; k^{1 / 4} 0.74$ ) sensitivities ( 0.94 vs 0.94 ), specificities (1.00 vs 1.00 ), positive predictive values ( 1.00 vs 1.00 ), negative predictive values ( 0.94 vs 0.80 ), and accuracies ( 0.97 vs 0.95 ) when compared to the reference standard. Conclusion: Although MRI remains the initial modality of choice in early diagnosing SpA, SPECT-CT appears diagnostically equivalent and should be considered a viable supplementary or alternative imaging modality particularly if there is contra-indication or inaccessibility to MRI.

References:

[1] Taurog J D, Chhabra A, Colbert R A. Ankylosing Spondylitis and Axial Spondyloarthritis[J]. N Engl J Med, 2016,375(13):1303.

[2] van der Linden S, Valkenburg H A, Cats A. Evaluation of diagnostic criteria for ankylosing spondylitis. A proposal for modification of the New York criteria[J]. Arthritis Rheum, 1984,27(4):361-368.

[3] Ward M M, Deodhar A, Gensler L S, et al. 2019 Update of the American College of Rheumatology/Spondylitis Association of America/Spondyloarthritis Research and Treatment Network Recommendations for the Treatment of Ankylosing Spondylitis and Nonradiographic Axial Spondyloarthritis[J]. Arthritis Rheumatol, 2019,71(10):1599-1613.

[4] Boonen A, Sieper J, van der Heijde D, et al. The burden of non-radiographic axial spondyloarthritis[J]. Semin Arthritis Rheum, 2015,44(5):556-562.

[5] Sieper J, Rudwaleit M, Baraliakos X, et al. The Assessment of SpondyloArthritis international Society (ASAS) handbook: a guide to assess spondyloarthritis[J]. Ann Rheum Dis, 2009,68 Suppl 2:i1-i44.

[6] Bermo M, Behnia S, Fair J, et al. Review of Extraskeletal Activity on Tc-99m Methylene Diphosphonate Bone Scintigraphy and Value of Cross-Sectional and SPECT-CT Imaging Correlation[J]. Curr Probl Diagn Radiol, 2018,47(5):324-332.

[7] Ward M M, Deodhar A, Akl E A, et al. American College of Rheumatology/ Spondylitis Association of America/Spondyloarthritis Research and Treatment Network 2015 Recommendations for the Treatment of Ankylosing Spondylitis and Nonradiographic Axial Spondyloarthritis[J]. Arthritis Rheumatol, 2016,68(2):282-298.

[8] Abdelhafez Y G, Hagge R J, Badawi R D, et al. Early and Delayed 99mTcMDP SPECT/CT Findings in Rheumatoid Arthritis and Osteoarthritis[J]. Clin Nucl Med, 2017,42(11):e480-e481. 